\title{
The Continuing Cautionary Tale of Creative Writing ETDs
}

Electronic theses and dissertations (ETDs) often spark debate regarding restrictions on access and students' opportunities for later publication. Most other studies have found publishers are in fact willing to work with submissions based on open access ETDs, but these studies have been conducted broadly on scholarly journals across a variety of disciplines rather than focusing specifically on creative writing. Librarians from East Carolina University identified a group of creative writing publishers and surveyed them to determine their attitudes towards manuscript submissions from ETDs, embargoes, and restrictions on access. Survey respondents by and large view open access ETDs as prior publications, although many are still willing to work with authors on an individual basis. The authors discuss the continued importance of offering creative writers options for restricted access and/or embargoes while publishers and creative writers work out the place of ETDs in the publishing chain.

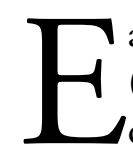

ast Carolina University (ECU) is a research-intensive doctoral-granting university of 27,000 students in Greenville, North Carolina. ECU offered a pilot for electronic theses and dissertations (ETDs) in the spring and fall semesters of 2009 and then began requiring them of all students in the spring of 2010. Planning for ETDs included negotiations with the Graduate School on the accessibility of the theses. Of special concern was whether there would be any way to restrict access, both for audience (who could view the theses) and for a specified time period (an embargo). Negotiations resulted in the following: ETDs are filed under a non-exclusive distribution license which gives students options for immediate online access, or after an embargo period of six months, one year or two years. Students may renew the embargo in one year increments. Thesis writers also select the level of access, whether open or restricted to campus users. ETDs are delivered first to ProQuest and then ingested into the University's institutional repository with the restrictions noted in the license for both ProQuest and local distribution.
One of the concerns expressed during ETD planning focused on the students' ability to market their work for later publication. During campus forums, professors from the creative writing program were particularly vocal regarding their desires for students to be able to restrict access to their theses and to protect their intellectual property rights. ECU offers a Master of Arts in English with emphasis on creative writing; another creative writing degree is a Master of Fine Arts (MFA) in Creative Writing. For simplicity, this paper will refer collectively to creative writing degrees as MFAs. While other studies have found that many publishers, especially those in the social sciences and science and technology subjects, do not see opening access to ETDs as a threat to future opportunities to publish them, there has not previously been a study designed to gauge creative writing publishers' perceptions of the impact of making theses freely available online ETDs will have on their future publishing potential. Such a study should be helpful in advising students regarding options between open and restricted access to their creative writing theses.

\section{Literature Review}

When considering such a survey, the authors wanted to build on existing literature and see how librarians' reports compared to views from within the field of creative writing. There seems to be, however, a conspicuous absence of discussion of ETDs within the literature of English. Since there were so few publications on the topic, they will be discussed first, and the librarian literature afterward.

Susan Lang (2002) asks whether English Departments are "Preparing Students for Our Past or Their Futures." She suggests that this moment in graduate education presents an opportunity for English Departments to examine critically what dissertations should do. She addresses the issue of electronic distribution more than potential loss of publisher revenue (an issue that arises also for the Association of Writers and Writing Programs (AWP) see below). Lang stresses another concern, the issue of qualitative review of ETDs, when she asks whether "dissertations that have only undergone faculty review (as opposed to blind peer review) are fit for distribution" (691). The relationship 
between qualitative review and publication status is important to many other stakeholders, as well.

Jude Edminster and Joe Moxley are two other professors in English writing about ETDs. In Computers and Composition they published "Graduate Education and the Evolving Genre of Electronic Theses and Dissertations" (2002). While discussing a variety of topics, the authors recognize that some faculty and students may have concerns about ETDs being prior publications. However, they urge universities to "recognize the potential value of accessible" ETDs because they "reflect an institution's ability to lead students and support original work" (101). That is, universities can use the high quality of their ETDs to maintain a high status and attract new students. Edminster further suggests that graduating students can also take advantage of the accessibility of their ETDs to "achieve earlier notoriety within their fields" (2006a, 137). While Moxley continued his support of ETDs being as widely available as possible (see, for instance, "Dissertating in a Digital Age"), Edminster has qualifications on her support of ETDs. She urges students to consider how their ETDs function in the "flow of power through the network of social relations in academe" (2006a, 139). Edminster also presented at the Ninth International Symposium on Electronic Theses and Dissertations about the apprehension of the creative writing program at Bowling Green State University regarding the potential impacts of ETDs on their recruitment and their students' ability to have their works published (2006b). This presentation expresses creative writers' and publishers' concerns about first rights of publication and their feelings that ETDs relinquish those rights, thus dramatically restricting venues for publication. Edminster concludes by suggesting ways the ETD process could be altered for creative writing. Among her suggestions are that repositories allow for an abstract only option, a password protected option, a non-download option and a paper only option.

Beth Kaufka and Jennifer Bryan, former students in Bowling Green State University's (BGSU) Master of Fine Arts (MFA) program who are now professors there, made their "Case against Electronic Theses" (2007). They state unequivocally that for creative writers, an ETD is a prior publication, and as such it endangers their opportunities not only for publication, but also for securing literary agents and perhaps also for securing teaching positions. Kaufka and Bryan present data from BGSU graduates over 38 years, showing that 64 percent of the MFA graduates published their first book after more than five years, and 43 percent of them took more than ten years. Although Kaufka and Bryan do not mention whether these first books were based exclusively or even substantially on the MFA theses, showing that publication can take this long is an important factor for ETD administrators in deciding whether to make an exception for MFA theses. BGSU's united MFA student body were successful in their campaign to allow MFA students to submit paper copies of their theses rather than fulltext ETDs.

Issues related to electronic theses and dissertations have received more treatment within the literature of Library Science. The issue of prior publication appears among the first conferences devoted to ETDs, and continues to the most recent.
Eugene Garfield's presentation at the Third International Symposium on Electronic Theses and Dissertations (2000), argues that '"prior' distribution [of the ideas behind the article] increases critical refereeing by peers which is so important to improving the quality of what gets published" (4). Garfield, whose background is in science publishing, supports open access ETDs because of their potential to improve the quality of published literature. Reporting from the Fourth International Symposium on ETDs, Gail McMillan answers the question "Do ETDs Deter Publishers" with the refrain that will be found in succeeding studies: "there is more a perception of a problem than actual evidence of a problem" $(2001,621)$. McMillan referrs not only to a panel during that conference, but also to survey data collected by Joan Dalton and Nancy Seamans.

Dalton and Seamans collaborate on a chapter within Electronic Theses and Dissertations: A Sourcebook for Educators, Students, and Librarians titled "Electronic Theses and Dissertations: Two Surveys of Editors and Publishers" (2004). Dalton's survey focuses on journal publishers in social science, science and medicine, while Seaman's survey was broadened to include publishers of humanities journals and several popular journals. It is unclear whether creative writing journals were included in either survey. In these comparatively early surveys, editors did not consistently define published in an online environment - that is, they did not consistently identify whether an open access ETD was a prior publication or not-although several criteria inform their decision-making. These criteria are still relevant when trying to determine whether articles 
derived from ETDs might not be publishable: peer review, level of access, lack of content revision, and stability within the scholarly record.

There were two important findings among these surveys: first, that publishers most often consider ETDs to be prior publications when they are not revised before submission and when they are widely distributed, and second, that a significant proportion of publishers would still consider an ETD for publication on an individual basis, indicating a willingness to work with authors. Seamans had also earlier shared observations based on her and Dalton's surveys in "Electronic Theses and Dissertations as Prior Publications: What the Editors Say" (2003). Significant especially in light of creative writing ETDs, one of the survey respondents identifies the central issue as "public access to the finished work. If that is available, then the work does not require another outlet-hence it is published" (59). There are many publishers who would be willing to consider publishing a book or article based on an ETD, but they stress the importance of revisions to that ETD, leading to a derived work. Results from the 2002 and 2004 ETD Surveys of Humanities Editors and Publishers lead librarians to similar conclusions.

Peter Suber (2008) approaches ETDs as a staunch advocate for open access. He mentions the Inglefinger rule, which is when a distributed preprint is cause for a publisher to not publish an article, and states that is does not apply to theses and dissertations. Suber says that the Ingelfinger rule is not valid for universities because they have for a long time submitted ETDs to UMI to distribute such scholarship. Suber notes that opposition to open access
ETDs often arises from faculty advisors, and argues nearly all ETDs should be open access for the benefit of the institution sponsoring the scholarship.

The Eleventh International Symposium on Electronic Theses and Dissertations includes a significant contribution from John Hagen, director of the ETD program at West Virginia University. In "Open Sesame: From Student Success towards Faculty Research Contributions in Institutional Repositories," Hagen highlights successes discovered by students in history and creative writing who have granted open access to their ETDs. In particular, his survey of publishing outcomes based on WVU's creative writing theses from 2002 to 2007 finds that 69 percent of students who grant open access to their ETDs have more success in publishing. Bluntly Hagen reminds his audience that theses are examination documents required in partial fulfillment of a degree, and that no one should base their careers only on the works in a thesis. Hagen believes creative writers can promote themselves with their ETDs, leading to future success.

More recently, Hagen moderated a panel discussion on the "Quandaries of Creative Writing, ETDs and Open Access" (2011). Panelists include the Executive Director of the AWP and two MFA faculty members discussing how best to balance publishing realities for this discipline and the schools' desire to provide access to their graduates' works. The AWP's argument against open access centers on how limiting access to these artistic works serves the "common good" just as importantly as opening access to scientific or medical ETDs. One of the MFA panelists notes that the very definition of published has changed in recent years, complicating the relationship between publishers and institutions. Hagen asks panelists the average time span between graduation and publication; the answer he receives, "it varies," does not provide clear guidance on embargo periods. Although he continues to support open access when possible, Hagen and other attendees report that they make concessions for creative writers on their campuses.

For the Thirteenth International Symposium on Electronic Theses and Dissertations, Angela McCutcheon (2010a) tackles again the question of whether publishers are rejecting submissions based on open access ETDs. This presentation excerpts work from her dissertation (2010b), which surveys personnel who work with their university ETD programs. While few universities report publication rejections caused by open access ETDs (two out of 109), she finds valid concerns within the fields of creative writing, chemistry, and history. The potential for rejection of creative writing submissions arises primarily because the submissions are not revised. While McCutcheon does cite Hagen and the successes he found at WVU, she also finds reasons for caution. McCutcheon bases her reticence on changes in policy at five universities, the policy against ETDs by the Association of Writers and Writing Programs, and on three rejections that one creative writer reported to her sponsoring university. Overall, though, McCutcheon believes that university ETD programs can continue their current mix of open, embargo, and restricted options for students because this mix meets the needs of publishers.

The most current survey of social sciences and humanities publishers was conducted by Marisa Ramirez, Joan Dalton, Gail McMillan, Max Read, and Nancy Seamans, reported 
at the Fourteenth International Symposium on Electronic Theses and Dissertations (2011), and recently accepted for publication (2012). Building on Dalton's, McMillan's, and Seamans' earlier work, these authors find that 83 percent of humanities and social sciences journal editors will consider publishing an article based on open access ETDs, and only 3 percent of the editors would never consider submissions based on them. Their findings resonate with earlier studies, particularly in the attention editors draw to the need for revisions to the ETD manuscripts. Ramirez et al. also report on the added value editors offer in peer review, revisions based on audience and authorial voice, and perhaps most important: the stamp of authority, the validation, offered by publication with that press or in that journal (2012, 10-11).

Early research into ETDs focuses on student and advisor concerns regarding ETDs and whether they will be seen as prior publication, thus limiting the students' chances of future publication. Conducted widely across a variety of subject areas, these ETD studies share three themes: First, it seems that every survey of publishers to date finds students' concerns about ETDs being prior publications are much larger than the publishers' reality. Second, for almost all publishers, the concept of derived works enters into publication consideration. This means that publishers consider ETDs to need editing and revising, therefore they are eligible for submission because the resulting publications will be derived works. It is important to note that these statements almost always describe scholarly publications, and are more often applied to dissertations than theses. Third, the concept of ETDs is still new enough to publishers that some have not created applicable guidelines.

We wanted to determine whether creative writing fits within the three themes named above. Will editors of creative writing magazines consider publishing submissions based on ETDs? There has to date been no other survey only of creative writing publishers and what they would do with submissions based on ETDs. The following IRB-exempt study should permit librarians to offer more informed advice on creative writing ETDs.

\section{Methods}

To get answers to whether creative writing thesis should be made open access, we identified a survey pool of current creative writing magazines from two standard librarian serials indexes: Magazines for Libraries and Ulrichsweb. Reviewed titles in the Magazines for Libraries categories of Fiction (including General, Mystery, and Science Fiction \& Fantasy), Literary Reviews, and Little Magazines were examined; Ulrichs subject headings such as Literature, Poetry, or Literary and Political Reviews were used (and combined with a preference for titles reviewed in any issue of Magazines for Libraries) to identify our final pool of 188 creative writing publications. We used only those published in English in the United States which would accept fiction, creative nonfiction, or poetry from new writers, and those publications for which we could find an editor's contact information.

The primary contact information sought for each magazine was an email address for the editor. Email addresses were identified in the Ulrichsweb records or by searching for the publication's website. When no email address was found (or when an email was returned with an invalid address), researchers searched for a contact telephone number. Although the total pool of editors receiving the survey was relatively small, our intent was more to gain a sense of trends than to conduct a thorough and statistically valid survey. It is possible that bias was introduced to this survey by permitting respondents to skip questions, page through the survey, change their answers, and/ or exit at any time. The pool of magazines, we felt, was sufficient to provide an indication of the attitudes of editors.

A survey with sixteen questions was developed and refined in consultation with a local editor. It was then distributed by email on March 6, 2012, with one follow-up email after four weeks. The email pointed to the survey online at SurveyMonkey. Some publishers were called and the survey administered by telephone. Telephone interviewees were given the same questions. The last survey response was collected six weeks later, on April 17, 2012. Questions were divided into groups: early questions were designed to gather some descriptive details about the publications themselves, followed by questions on the editors' perceptions of print and electronic theses, and a third group oriented on revisions to manuscripts. The last question was an open-ended exploration of how the availability of ETDs impacts the publication of magazines dedicated to creative writing. Fiftytwo publishers began the survey, and forty-six completed it, for a return rate of 24 percent. While perhaps not statistically significant, the return rate is not far out of line with other studies in the literature. We believe that the results which follow provide adequate evidence of creative writing publishers' attitudes toward ETDs. 


\section{Results}

What kinds of publications were represented among our survey data? Poetry was the most common type, representing fifty of the fifty-two responses. Creative fiction was published in forty-six of the journals whose editors responded, and creative nonfiction appeared in forty. Thirtyone respondents indicated other types of works in their publications, notably book reviews and artwork, but they also included interviews and scholarly articles. Many of the magazines represented are affiliated with universities - thirty-four of the fiftytwo, as opposed to eighteen which are not. The authors were curious about whether a university affiliation would influence the publisher's perception of ETDs, but both types of publications had the same range of answers. All respondents indicated that they would consider publishing works by new and/or previously-unpublished authors, a key question since we are operating under the assumption that students in creative writing programs could be fairly described this way.

We were also curious about whether creative writing magazines would offer online access, and fifteen of the respondents answering question four report having online access available for all the creative writing they publish. The largest number of respondents, though-twentynine of them-report having "some" materials available online. Only eight of the respondents indicated no materials are online. Many of the explanations indicate a dependence on a print subscription base. A few comments referred explicitly to the editors' preference for their readers to interact with a print format over an online format. In fact, all but three of the responses that mention subscriptions tied them exclusively to the print format, and one respondent stated baldly, "We exist because of paper subscriptions." Although the question does not distinguish between subscription access only and materials that are freely available online, free text responses indicate that some editors interpreted the question to refer only to free access. Some editors, though, indicated that their magazines provide at least some digital content to entice readers to buy the print (six comments), while a handful of other comments expressed interest in digitizing content. Most of these respondents were concerned about the time required to do so. Some planned to start digitization with back issues.

When initially asked in question seven whether the editors would consider publishing something that came from an author's thesis, almost all (nearly 96 percent) said they would: while most (73 percent) said that all submissions are welcome, others (about 21 percent) would accept at least some material from theses, and a small number (2 percent) said thesis submissions were fine as long as the author had significantly revised the work. Only a few publishers ( 4.5 percent) said that they would not publish work from a thesis. These results mirror findings from surveys reported by Ramirez et al. (2012) and McMillan (2001), suggesting that most publishers would accept submissions based on theses. This question purposely came at the beginning of the survey, before we had asked any questions pertaining explicitly to ETDs. We wondered whether the heavy slant towards accepting submissions from theses, especially those without revision, suggested that the editors of literary magazines were still thinking primarily of print theses.

An overwhelming majority of editors do not check to see if works they wish to publish are from ETDs. In comments for this question one respondent said: "We expect the author to inform us of the status of any submission. If we learn that a manuscript has been previously published we automatically reject it. If we learn after publication, we will no longer accept work from that writer." Another editor highlighted an interesting point: "I don't ask and I have no memory of anyone telling me that a work was from a thesis. Sometimes work finds its way into larger works, but most of my writers are mature, professional writers in mid-career, academics, and others. Students rarely have the kind of chops that impress me as an editor." A third respondent said that his editors do not regularly check to see if material they wish to publish is from a MFA thesis and then followed up with this comment, "But we will... if and when electronic theses are unrestricted, freely available to general readers online." The editors we worked with seemed to think that ETDs are in the future, but for many students they are currently a requirement for their degree. It is interesting to note that one local creative writing professor told us that it took him more than ten years to publish works started in his MFA thesis. So, while editors may think submissions are not coming from theses, it is possible that quite a few got their start there.

After introducing the idea of ETDs, question ten asked pointblank whether editors consider a thesis a prior publication. Twentythree of thirty-nine (57 percent) said they do. While some (eight of these twenty-three respondents) feel that both print and electronic theses are prior publications, a larger number of them (fifteen) said that only ETDs are prior publications. These responses represent the sentiment 
that if the work is freely available, it is published. [See figure 1]

Most editors stressed that when they publish a work, they want first publication rights to that manuscript. One editor put it this way: if the work is, "widely distributed online that would constitute prior publication; it doesn't matter if it is free or not. The point is that we do not want to publish work that is already available elsewhere." Again, the idea of a print thesis being only available to one or two people on campus came up when asked about prior publications: "It's about access/distribution. Internet is global. A print copy in an advisor's office isn't distributed. A print copy in circulation is distributed." Another respondent said "The public doesn't go out to seek print theses, so I consider those unpublished." Most editors seem unaware that for many universities print theses do circulate and can be shared via interlibrary loan. Also, the "publishability" of a derived work came up again here. A few editors, in the open response field for this question, mentioned that if a thesis manuscript were significantly revised, then they would consider publishing it.

Most of the editors (80 percent) would be willing to publish submissions from a print thesis. While only 37 percent agreed to publish from a freely-available ETD, 63 percent would not, even if revised. Of those editors who would not publish from a freely available thesis, 88 percent of them changed their minds if access to that ETD were restricted. All the respondents who did not view theses as prior publications would publish materials from both print or electronic theses - 63 percent of them even if the ETDs were freely-available. It is clear, though, that in general editors are not comfortable with ETDs that are freely available online. It seems that if access is controlled in some way most of their concerns would be alleviated. [See figure 2]

Near the end of the survey, we asked a pair of questions related to embargoes, in hopes of establishing what advice might be most beneficial for graduating students. One question asked about the embargo length, and the other question asked about the audience who could read the thesis after the embargo period. While only thirty-eight respondents answered this question, for 61 percent of the publishers, a two-year embargo would be sufficient. And nearly half (seventeen of the thirtyeight) indicated that a one-year embargo would be sufficient. Thirtytwo percent of the respondents (twelve) wanted the ETD never to be available, and another three publishers wanted the embargo period to last at least five years. Twothirds of these "five-year or never" publishers believed that ETDs are a prior publication. Only one of the fifteen in the "five or never" group was comfortable with free online availability after the embargo period, while three in that group suggested

\section{Do you consider a thesis a prior publication?}

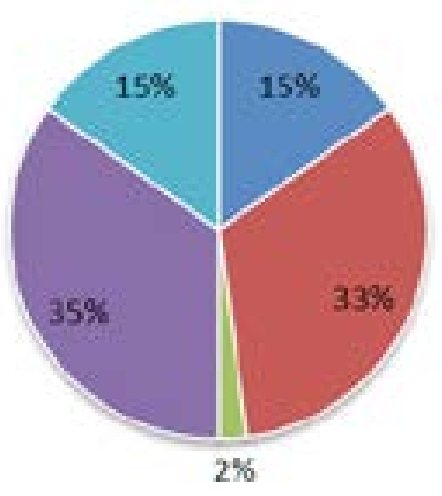
eleven respondents ( 73 percent)
wanted no one to be able to access
the ETD. In contrast, eighteen of
the twenty-three in the "one or two-
year embargo" group ( 78 percent)
were comfortable with the ETDs
being freely available after embargo,
and only four (17 percent) wanted
restricted access afterward. One
member of the "one or two-year
embargo" group did not answer the
question about availability afterward.
The next two questions asked
about revisions of the manuscript.
One asked about the normal amount
of revisions required for submissions
based on a thesis, and the other asked
on what basis those revisions were
determined. Publishers could answer
that they required extensive revisions
often or occasionally, moderate
revisions often or occasionally,
or that they required few or no
revisions. The most common answer
was that moderate revisions were
required (eighteen of thirty-eight,
for 47 percent). Nine publishers ( 24
percent) indicated that they require
extensive revisions, but a surprising
eleven ( 29 percent) answered that
they require few or no revisions. or that they required few or no for 47 percent). Nine publishers (24 percent) indicated that they require extensive revisions, but a surprising eleven (29 percent) answered that they require few or no revisions. 
The second question in this pair asked publishers the bases for their revisions; publishers could answer all that applied. Reponses included that revisions were based on differentiating the published work from the thesis, on recommendations from reviewers, or on the quality of the writing. Publishers were also given an "other" free text option. Of the thirty-four publishers who answered this question, the quality of writing was by far the most common answer, with thirty-one (82 percent) selecting it. The next most common answer was recommendations from reviewers, with ten respondents (26 percent). Only five publishers (13 percent) indicated a desire to differentiate the published work from the thesis. There were few free text responses here, and most of them simply reinforced one of two views: that revision was necessary on occasion, or that the publisher would reject any piece of writing in need of revision. Altogether, these results and comments suggest a greater unwillingness to revise creative writing than we had expected-and this unwillingness to revise means that publications based on ETDs are less likely to be viewed as derived works.

The final question was openended: "How does the availability of ETDs impact the publication of journals dedicated to creative writing?" Thirty-eight respondents recorded comments on a variety of related insights, but many were concerned about their markets being affected. Twenty-one of the comments expressed concern over their publications not being able to claim the first opportunities to present creative materials, and thirteen comments explicitly equated ETDs with prior publication. Only one editor wrote that ETDs were not the equivalent of publishing. While one editor suggested that ETDs would make less work available for publishing, this comment might be juxtaposed with one that claims no impact because their journal gets more than 4,000 submissions per year. Notably, two other editors suggested that ETDs' impacts were greater on creative writing graduates than on publishers. One comment of note expresses worry that electronic publications will threaten the very existence of print journals, which this

\section{Would you publish content from a thesis if it was a}

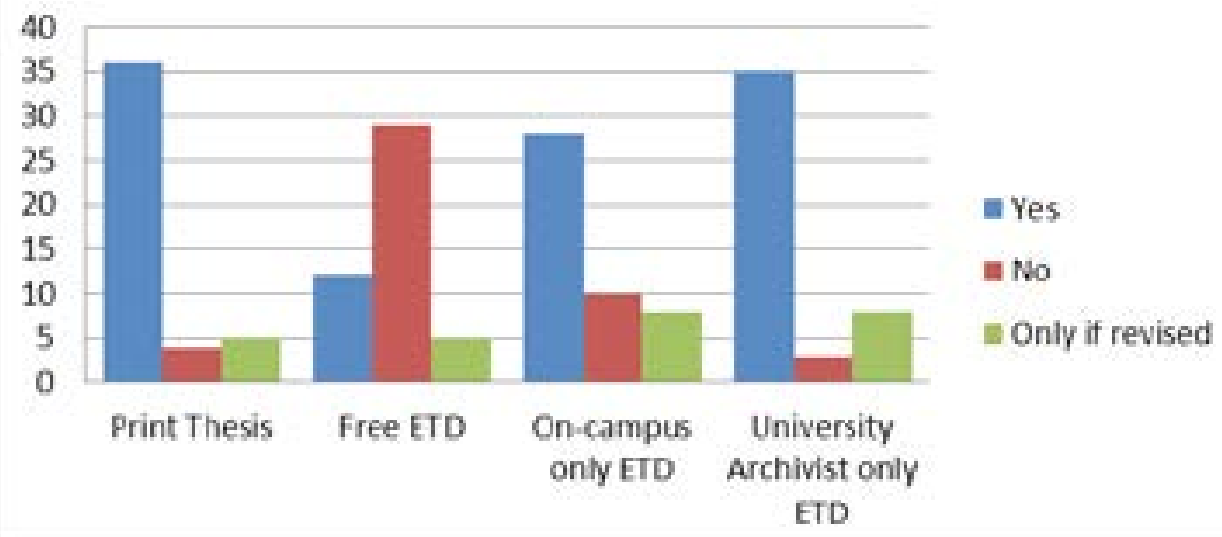

Figure 2 editor is anxious to protect. Another significant comment gets at the crux of ETDs as prior publications by asking if they truly create competition for readers: "I think that may depend on how popular electronic theses become with the readership of literary journals. Are our readers likely to be reading theses from MFA granting institutions?" The issue most of concern to editors, then, is first rights to publication. Within our analysis of these comments, though, we are curious about exactly why creative writing editors feel threatened by ETDs - the idea that "publishing" (whatever that means these days) occurs outside journal channels, or the perception that they are competing for readers, or discomfort with how electronic and print publishing should coexist?

\section{Discussion}

The publishers' approach to ETDs as source material for their publications is far different from that of the faculty and students toward what is by definition an examination document written in partial completion of the requirements to a degree. In this sense, ETDs function as a certification of degree-they acknowledge that their authors have achieved an educational benchmark. Some publishers, though, view the requirement of ETDs to be unethical, claiming that libraries and universities are stealing first publication rights. Of course, this argument depends on two facts: first, that creative writing publishers are publishing essentially the same works that were presented to the university committees and not requiring revisions; and second, that ETDs create competition for readers of creative writing magazines, an assertion that has not been studied and reported on within library literature. 
Publication in creative writing journals serves a different function than that of ETDs: validation. That is, the journal's stamp of authority lets readers know that these creative works are high quality. Because this validation function in turn reinforces the journal's profile, first publication rights are jealously sought by editors. Many faculty advisors in creative writing are sympathetic to publishers' assertions that ETDs impede their students' first sales rights. The Association of Writers \& Writing Programs (AWP) is an accrediting body for creative writing programs, and has established its "Policy on Electronic Theses and Dissertations." The AWP sees the issue as one of first publication rights as well, stating that "universal dissemination" of ETDs markedly reduces students' publication opportunities. However, the AWP policy goes on to state "Such sales of first serial rights help the work reach a wide public audience." Is the AWP more concerned about the size audience a work can have or about its sales? With ETDs the audience can be anyone with a Web connection, but there are not necessarily sales involved. AWP says that restricting audiences early on for a work will result in that work having a greater audience later when it is published in a journal. We contend, though, that greater access creates a greater audience, and that could be the most important issue for writers struggling to win recognition of their talents.

Perhaps it is time to think of ETDs differently, to try to find a way for universities to reap rewards from ETDs and for writers to reap rewards for their creative works. Perhaps it is time for ETDs to serve both certification and validation functions. In addition to certifying the degree, ETDs could be used as a way to validate for general audiences the superior work produced by graduates of that particular program. Since some publishers consider open access ETDs as prior publications, students should take advantage of the publicity, with the faculty guidance of committee members serving as the authoritative stamp of editorial approval. Work submitted for the MFA thesis is supposed to be publishable quality; therefore, committee approval would validate it as a true publication. This idea is not new: Edminster and Moxley have both hinted at it (Edminster and Moxley 101; Edminster 2006a, 137), and it is a simple extension of an idea promulgated in the Networked Digital Library of Theses and Dissertations (NDLTD) resources for "students to market their creative ETDs effectively while still... soliciting another of their creative works" for traditional publication. In fact, there might be few additional steps required to turn creative writing ETDs into university publications: for instance universities could certainly apply for an ISBN and contract for print-on-demand sales if such sales were of interest. Universities would benefit if prospective MFA students could see the quality of writing previous students have produced at that institution. Students would benefit by having a published work.

Creative writing publishers' relationship with online publishing is still in its infancy. As a group they seemed to think that ETDs are in the future; some admitted to never having given them a thought before our survey. If publishers do not keep abreast of technological developments in publishing along with the changes in ETD requirements, and if they are so willing to trust their authors as mentioned above, it seems that they will inadvertently publish works that were part of ETDs (or have done so already). In addition, publishers should consider what other creative writing is already available on the Web. What audience are the publishers trying to reach? Can their validation help demarcate the quality of works available online? Multiple exposure points provided by enabling both online content and print content would surely benefit these magazines (just as any other journal), and may help raise their readership.

\section{Next Steps}

One thing is clear: for the time being, libraries must continue to offer closed access to electronic theses. While publisher and writer attitudes evolve on the topic, allowing some sort of closed access option satisfies the "no prior publication" rule of the majority of the publishers queried. Campusonly access and two year renewable embargoes seem sufficient based on the results of this survey. However, to be more generally applicable, further research into creative writing publications derived from masters' theses is needed. In addition, a more comprehensive survey of publishers would inform ETD professionals of the need to keep closed access options for creative writers.

Conducting a survey of creative writing publishers' attitudes toward ETDs allowed us to confirm in large part the major concerns. Chief among those concerns is that publishers consider open access ETDs to be prior publications. While creative writing publishers determine ways to maximize their relationship with online publishing, we suggest that creative writing programs consider having their ETDs serve both certification and validation functions mentioned above. Librarians will be able to counsel creative writing students on embargo and restriction options in light of these findings. 


\section{References}

AWP policy on electronic theses and dissertations. (2012). In The AWP director's handbook: A Compendium of guidelines and information for directors of creative writing programs. Retrieved from http://www. awpwriter.org/membership/dh_8. htm.

Churm, O. (2011, January 7). Growing concern over digital thesis deposit [Web log post]. Retrieved from http://www. insidehighered.com/blogs/ the_education_of_oronte_churm/ growing_concern_over_digital_ thesis_deposit

Dalton, J., \& Seamans, N. (2004). Electronic theses and dissertations: Two surveys of editors and publishers. In E. Fox, (Ed.), Electronic theses and dissertations: A sourcebook for educators, students, and librarians (pp. 247-266). Retrieved from http://digitalarchive.gsu.edu/ univ_lib_facpub/47.

Dalton, J. (2000). Electronic theses \& dissertations: A survey of editors and publishers. Proceedings of Third International Symposium on Electronic Theses and Dissertations, USA. Retrieved from http://snidely. dlib.vt.edu:8081/dspace/ bitstream/2340/169/2/etd_ presentation.pdf.

Digital Library and Archives (DLA), Virginia Tech. (2002). Viewing results for 2002 ETD survey of humanities editors and publishers. [Survey]. Retrieved from http://lumiere.lib.vt.edu/ surveys/results/.

Digital Library and Archives (DLA), Virginia Tech. (2004). Viewing results for 2004 ETD survey of humanities editors and publishers. [Survey]. Retrieved from http://lumiere.lib.vt.edu/ surveys/results/.

Douglas, K. (2003). To restrict or not to restrict access: The $\mathrm{PhD}$ candidate's intellectual property dilemma. Proceedings of Sixth Symposium on Electronic Theses and Dissertations, Germany. Retrieved from http:// docs.ndltd.org:8081/dspace/ bitstream/2340/604/1/index.pdf.

Edminster, J. (2006a). Electronic theses and dissertations: constructing professional interest over and against resistance to innovation. In J. Inman \& B. Hewett (Eds.) Technology and English studies: innovative and professional paths (pp 131-142). Mahwah, NJ: Lawrence Erlbaum Associates.

Edminster, J. (2006b). Intellectual property and mandatory ETDs that constitute literary works of art: A case study of one creative writing program's efforts to achieve solutions. Paper presented at ETD2006: The Ninth International Symposium on Electronic Theses and Dissertations, Canada. Retrieved from http://www6.bibl.ulaval. ca:8080/etd2006/pages/papers/ SP5_Jude_Edminster.ppt.

Edminster, J., \& Moxley, J. (2002). Graduate education and the evolving genre of electronic theses and dissertations. Computers and Composition, 19(1), 89-104. doi: 10.1016/S8755-4615(02)000828.

ETDs and future publication potential for graduate students. (2011). Networked Digital Library of Theses and Dissertations. Retrieved from http://www.ndltd.org/resources/ statement-about-web-publication.
Foster, A. (2008, May 16). Readers not wanted: student writers fight to keep their work off the web. The Chronicle of Higher Education. Retrieved from http:// chronicle.com/article/ReadersNot-Wanted-Student/36171.

Foster, A. (2008, March 13). U. of Iowa writing students revolt against a plan they say would give away their work on the web. The Chronicle of Higher Education. Retrieved from http://chronicle. com/article/U-of-Iowa-WritingStudents/590/.

Garfield, E. (2000). Is acknowledged self-archiving prior publication? Proceedings of the Third International Symposium on Electronic Theses and Dissertations, USA. Retrieved from http://snidely. dlib.vt.edu:8081/dspace/ bitstream/2340/172/1/ETDTalkGarfield.pdf.

Hagen, J. Open sesame: From student success towards faculty research contributions in institutional repositories. Paper presented at ETD08: The Eleventh Annual Symposium on Electronic Theses and Dissertations, Scotland. Retrieved from http://www4.rgu.ac.uk/files/ Hagen\%20Open\%20Sesame.doc. Hagen, J., Fenza, D., Lachman, B., \& Pritchard, S. (2011). Publish or perish? A panel discussion on the quandaries of creative writing, ETDs, and open access. Discussion conducted at the United States Electronic Theses and Dissertation Association (USETDA) Conference, Orlando, FL. Retrieved from https://conferences.tdl.org/ USETDA/USETDA2011/paper/ viewFile/374/148.

Howard, J. (2012, April 3). The road from dissertation to book 
has a new pothole: The internet. The Chronicle of Higher Education. Retrieved from http:// chronicle.com/article/The-RoadFrom-Dissertation-to/126977.

Kaufka, B. \& Bryan, J. (2007, March/April). Workshop: The case against electronic theses. Poets \& Writers, 35(2), 99-102.

Lang, S. (2002). Electronic dissertations: Preparing students for our past or their futures? College English, 64(2), 680-695. Retrieved from http://www.jstor. org/stable/3250771.

MacDonald, J. (2011). Report on the 2011 Inaugural United States Electronic Theses and Dissertations Association (USETDA) Conference. D-Lib Magazine, 17(7/8). doi:10.1045/ july2011-macdonald.

McCutcheon, A. (2010a). Are ETD alumni reporting publisher rejections to ETD personnel within the United States? Paper presented at the meeting of ETD2010: The Thirteenth International Symposium on Electronic Theses and Dissertations, Austin, TX. Retrieved from https:// conferences.tdl.org/utlibraries/ etd2010/paper/view/15.

McCutcheon, A. (2010b). Impact of publishers' policy on electronic thesis and dissertation (ETD)distribution options within the United States. (Doctoral dissertation). Retrieved from http://rave. ohiolink.edu/etdc/view?acc_ num=ohiou 1273584209

McMillan, G., Ramirez, M., Dalton, J., Read, M., \& Seamans, N. (2011) An investigation of ETDS as prior publications: findings from the 2011 NDLTD publisher's survey. Proceedings of the 14th International Symposium on Electronic Theses and Dissertations, South Africa. Retrieved from http://dl.cs. uct.ac.za/conferences/etd2011/ papers/etd2011_mcmillan.pdf. McMillan, G. (2001). Do ETDs deter publishers? Coverage from the 4th International Symposium on ETDs. College \& Research Libraries News, 62(6), 620-621. Retrieved from http://search. ebscohost.com/login.aspx?direct= true \&db=llf\&AN=502874508\&s ite $=$ ehost-live.

Ramirez, M., Dalton, J., McMillan, G., Read, M., \& Seamans, N. (2012). Do open access electronic theses and dissertations diminish publishing opportunities in the social sciences and humanities? Findings from a 2011 survey of academic publishers. College
\& Research Libraries. Advance online publication retrieved from http://crl.acrl.org/content/ early/2012/04/05/crl-356.full. pdf + html.

Seamans, N. (2003). Electronic theses and dissertations as prior publications: what the editors say. Library $\mathrm{Hi}$ Tech, 21(1), 56-61. doi: $10.1108 / 07378830310467409$.

Suber, P. (2010). Open access for ETDs. Networked Digital Library of Theses and Dissertations.

Retrieved from http://www.ndltd. org/resources/publishers/openaccess-for-etds/.

Suber, P. (2008). Open access to electronic theses and dissertations. DESIDOC Journal of Library and Information Technology, 28(1), 25-34. Retrieved from http://publications.drdo.gov. in/ojs/index.php/djlit/article/ view/149/64.

Walker, J., \& Moxley, J.

Dissertating in a digital age: The future of composition scholarship. In N. Welch, K. Latterell, C. Moore \& and S. Carter-Tod (Eds.) The dissertation and the discipline: reinventing composition studies (pp. 110-118), Portsmouth, NH: Boynton-Cook.

\section{Appendix 1: Survey Questions}

What is the name of your journal? (Open text)

What kinds of works are included in your publication?

(Check all that apply)

- Creative fiction

- Creative nonfiction

- Poetry

- Other (please specify)
Is your journal published in association with a college or university?

- Yes

- No

Does your journal provide online access to the creative writing/poetry it publishes?

- Yes, all

- Some

- No 
If not all the material is available online, why? (Open text)

Do you consider published works by new and/or previously-unpublished authors?

- Yes

- No

Would you consider publishing a submission that came from the author's thesis?

- Yes, all submissions are welcome

- Some materials from theses may be acceptable

- Only submissions from theses that have been significantly revised are acceptable

- No

On receipt of a new manuscript, do you regularly check to find out whether it is based on a thesis?

\begin{tabular}{|l|c|c|c|}
\hline & Yes & $\begin{array}{c}\text { Yes, only if } \\
\text { revised }\end{array}$ & No \\
\hline Print thesis & $25 \%$ & $44 \%$ & $31 \%$ \\
\hline $\begin{array}{l}\text { Electronic thesis freely-available } \\
\text { online }\end{array}$ & $50 \%$ & $21 \%$ & $29 \%$ \\
\hline $\begin{array}{l}\text { Electronic thesis with access } \\
\text { restricted to campus }\end{array}$ & $14 \%$ & $20 \%$ & $66 \%$ \\
\hline $\begin{array}{l}\text { Electronic thesis accessible only } \\
\text { to university archivist }\end{array}$ & & & \\
\hline
\end{tabular}

- Yes

- Sometimes

- No

Would you consider publishing content from a manuscript if it met any of the criteria below?

(Check all that apply)

Do you consider a thesis prior publication?

- Yes for both print and electronic theses

- Yes for electronic theses

- Yes for print theses

- No
Would you publish materials from an ETD if that ETD were embargoed, but would become available after:

- One year

- Two years

- Five years

- Never

Would you publish materials from an ETD if that ETD were embargoed, but would later become available to:

- Anyone (freely-available online)

- University students and faculty only

- No one

If your journal agrees to publish a submission based on a thesis, how much revision is normally required?

- Extensive revisions often required

- Extensive revisions occasionally required

- Moderate revisions often required

- Moderate revisions occasionally required

- Few or no revisions

If your journal requires revisions to publish the manuscript, on what basis are those determined? (Check all that apply)

- Based on differentiating the published work from the thesis

- Based on recommendations from reviewers

- Based on the quality of the writing

How does the availability of ETDs impact the publication of journals dedicated to creative writing? (Open text)

May we contact you to follow up? Is so, enter one of the following:

- Email

- Telephone number

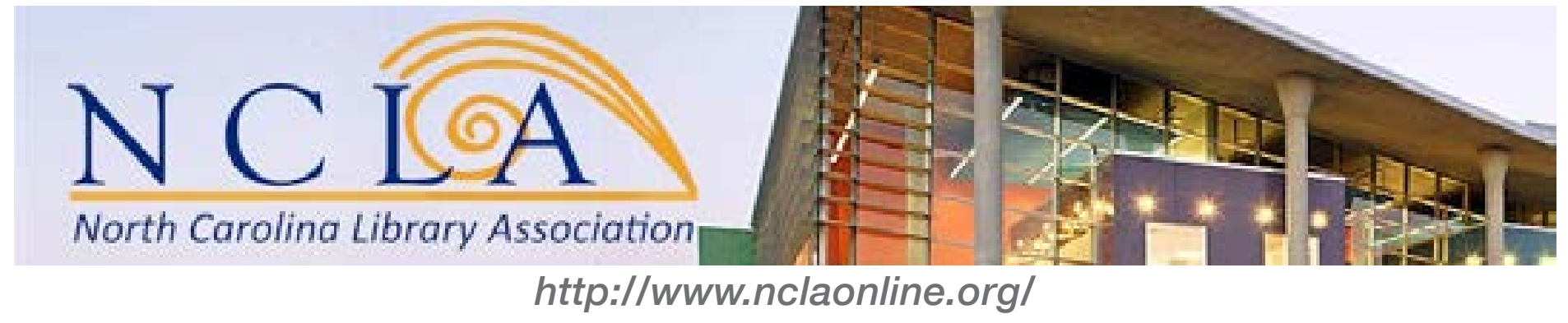

